\title{
Morphodynamic effects of stone and wooden groynes in a restored river reach
}

\author{
Bahaeldeen Zaid ${ }^{1, *}$, Paride Nardone ${ }^{1}$, Michael Nones $^{2}$, Christoph Gerstgraser ${ }^{3}$ and Katinka \\ Koll $^{1}$ \\ ${ }^{1}$ Leichtweiß-Institute for Hydraulic Engineering and Water Resources, TU Braunschweig, \\ Braunschweig, Germany \\ ${ }^{2}$ Interdepartmental Centre for Industrial Research in Building and Construction - Fluid Dynamics \\ Unit, University of Bologna, Bologna, Italy \\ ${ }^{3}$ Gerstgraser - Ingenieurbüro für Renaturierung, Cottbus, Germany
}

\begin{abstract}
Restoration works on an $11 \mathrm{~km}$ long reach of the Spree River near Cottbus in Germany were accomplished in 2014. The overall objective was to improve the biodiversity, changing the morphological structure from a straight single-thread river to a braiding one with reshaped thalweg, and creating zones with varying flow velocities required for fish spawning. Several interventions were made, among which also two types of groynes were constructed along the reach: impermeable stone groynes, with an inclined crest so that only the tip is typically submerged during normal flow conditions, and wooden groynes made of several large trunks, which are mainly submerged at normal flow conditions. To compare local morphodynamic effects caused by the different types, flow velocities and bed topography were measured at distances of $12 \mathrm{~m}$ upstream and $16 \mathrm{~m}$ downstream of two selected groynes. The vertical profile was captured by measuring at five levels above the bed. Bed material was sampled at several locations around the groynes. The analysis of the measurements showed the effect of each groyne type on the flow velocity, bed topography and bed material. Furthermore, the differences in the effects of each groyne type on the flow, bed topography and bed material were highlighted.
\end{abstract}

\section{Introduction}

Since centuries groynes are used in river management for protecting river banks and stabilizing the river course. For navigation they are used to maintain sufficient water depths (e.g. [1]). Nowadays many rivers in Europe are heavily channelized and, consequently, their habitat was negatively impacted. For mitigating the negative impacts of the river canalization, [2] already introduced different ways of using groynes to improve the fluvial habitat (Fig. 1). Several structures of groynes have been developed, e.g. bendway weirs (e.g. [3]), and studies were carried out to quantify the improvement of biodiversity (e.g. [4]).

* Corresponding author: b.zaid@tu-braunschweig.de 

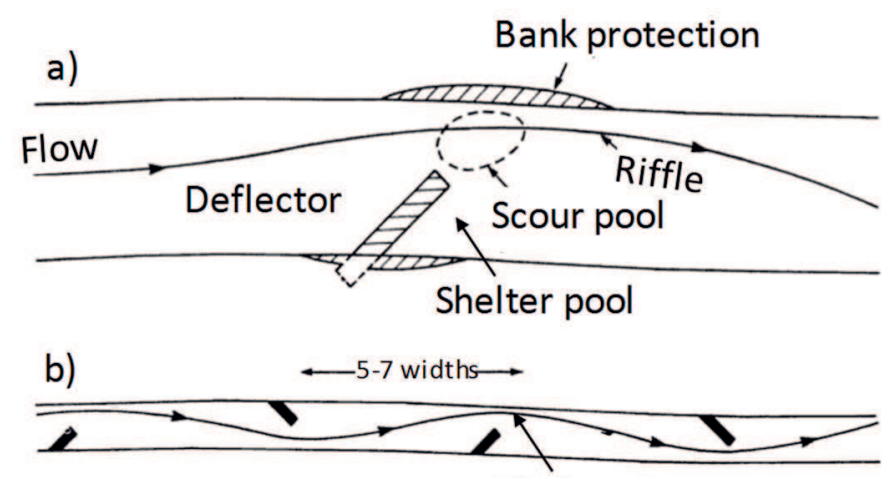

c)

Thalweg

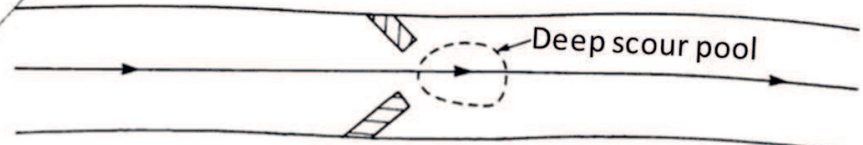

Fig. 1. Use of groynes to re-creation of (a) pool and riffle, (b) meander pattern, and (c) scour ([2]).

In a river restoration project along the Spree River in Germany, aiming to enhance the river structure $([5,6])$, among further interventions, two types of groynes were installed: stone groynes and groynes made of large wooden trunks. The project was initiated to compensate a destroyed Natura 2000 site in Brandenburg and it was started in 2006.

In 2015, one year after the completion of the restoration project, field measurements were carried out to evaluate the morphodynamic effect of the different types of groynes on the velocity distribution, the bed topography, and the composition of the bed material. The analysis of the data is presented.

\section{Study site}

The Spree River rises on the Lusatian Mountains at the Czech/Germany border and flows for about $380 \mathrm{~km}$ before it meets the Havel River, a tributary of the Elbe River, in the city of Berlin (Fig. 2a). The Spree River system is heavily affected by human interventions, such as agriculture and more than one century of coal mining [7]. Nevertheless, throughout its course a plurality of closely-spaced braided parts and semi-natural habitats can be found, such as the Spreewald, located downstream (northern) of the city of Cottbus (Fig. 2b).

The restored river reach is located approximately $10 \mathrm{~km}$ downstream of Cottbus (sub reach K1 in Fig. 2c). This reach drains a catchment area of about $62 \mathrm{~km}^{2}$, and has a longitudinal slope of around $0.07 \%$. The bankfull discharge is $35 \mathrm{~m}^{3} / \mathrm{s}$ and the mean discharge is $7.5 \mathrm{~m}^{3} / \mathrm{s}$. The river bed material is composed of fine sand with a median diameter of $0.66 \mathrm{~mm}[6]$.

The restoration works included several interventions to increase the flow variability and reconnect the floodplains to improve the overall ecological status [6-8]. Among the measures, groups of stone and wooden groynes were constructed to develop morphological structures.

The stone groynes are impermeable and the crest is inclined so that only the tip is submerged during normal flow conditions. The wooden groynes consist of several trunks arranged vertically allowing the flow to pass through. Typically, the structures are slightly submerged. The trunks are fixed to the bank and to wooden piles up- and downstream of the tip. 

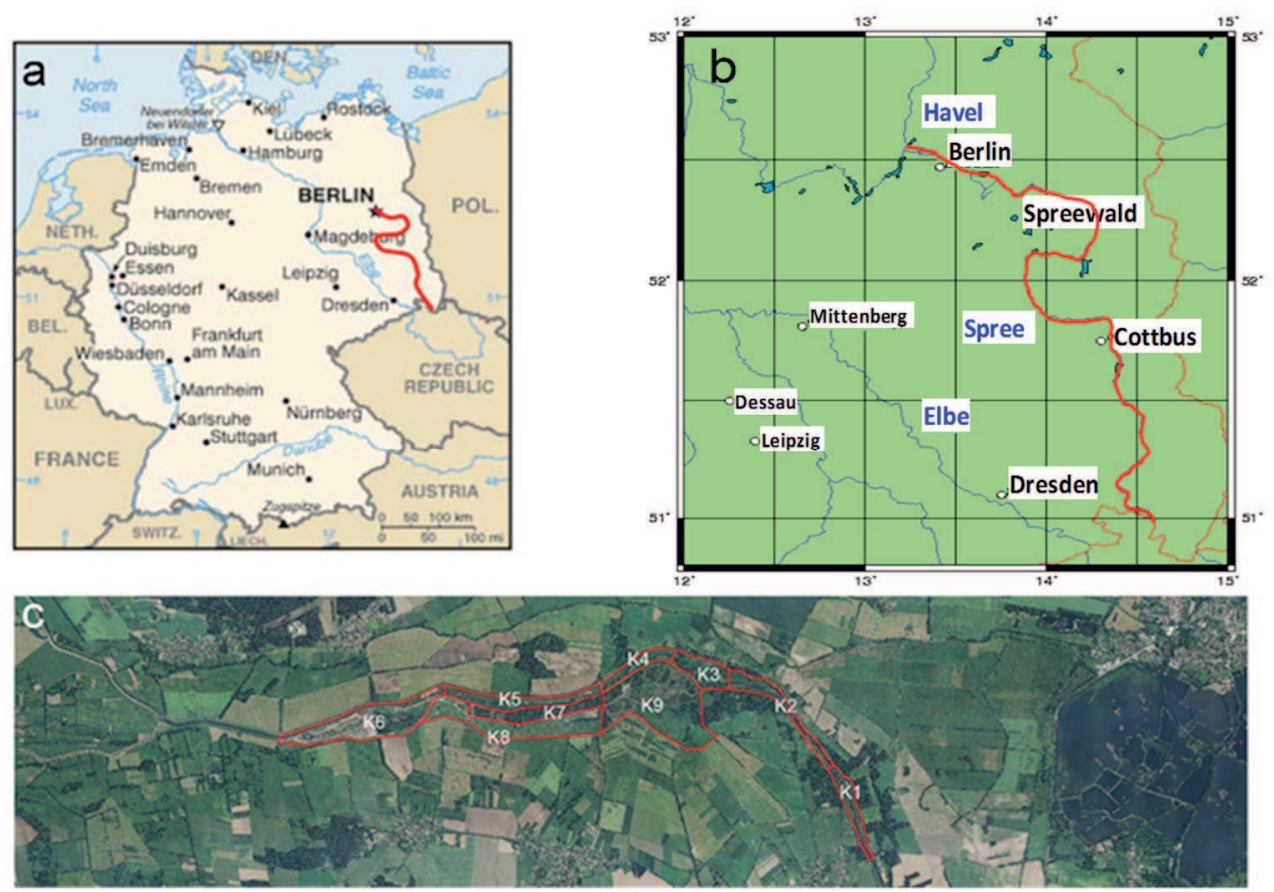

Fig. 2. a) Map of Germany, with the path of the Spree River; b) the watercourse in Saxony and Brandenburg; c) restored river reach, with indication of the various sub-reaches K1-K9, modified form [6].

\section{Field measurements}

\subsection{Measurements location}

Two groynes within the stone and wooden groyne fields, installed in a straight reach of the first area K1 of the restoration project (Fig. 2c), were selected. The river section had an average bankfull width of about $24 \mathrm{~m}$, and an average depth of $0.8 \mathrm{~m}$.

The measurements were done at the third stone groyne (StB-K1-3) on the left bank and at the first wooden groyne (RbB-K1-1) on the right bank, about $110 \mathrm{~m}$ downstream of the stone groyne (Fig. 3a). The measuring grids for velocity and river bed topography are shown in Fig. 3a. They extended $12 \mathrm{~m}$ upstream and $16 \mathrm{~m}$ downstream of each groyne, and across the river width. The spacing between the measurements was made finer close to the groyne $(2 \mathrm{~m})$, than away from the groyne $(4 \mathrm{~m})$. The vertical distribution of the grid for the velocity measurements was related to the local water depth with positions at 10, 20, 40, 60 and $80 \%$ of the water depth above the bed. Bed material samples were taken in the middle of the river and in the vicinity of each groyne. The sampling positions are indicated in Fig. 3a. 
a)
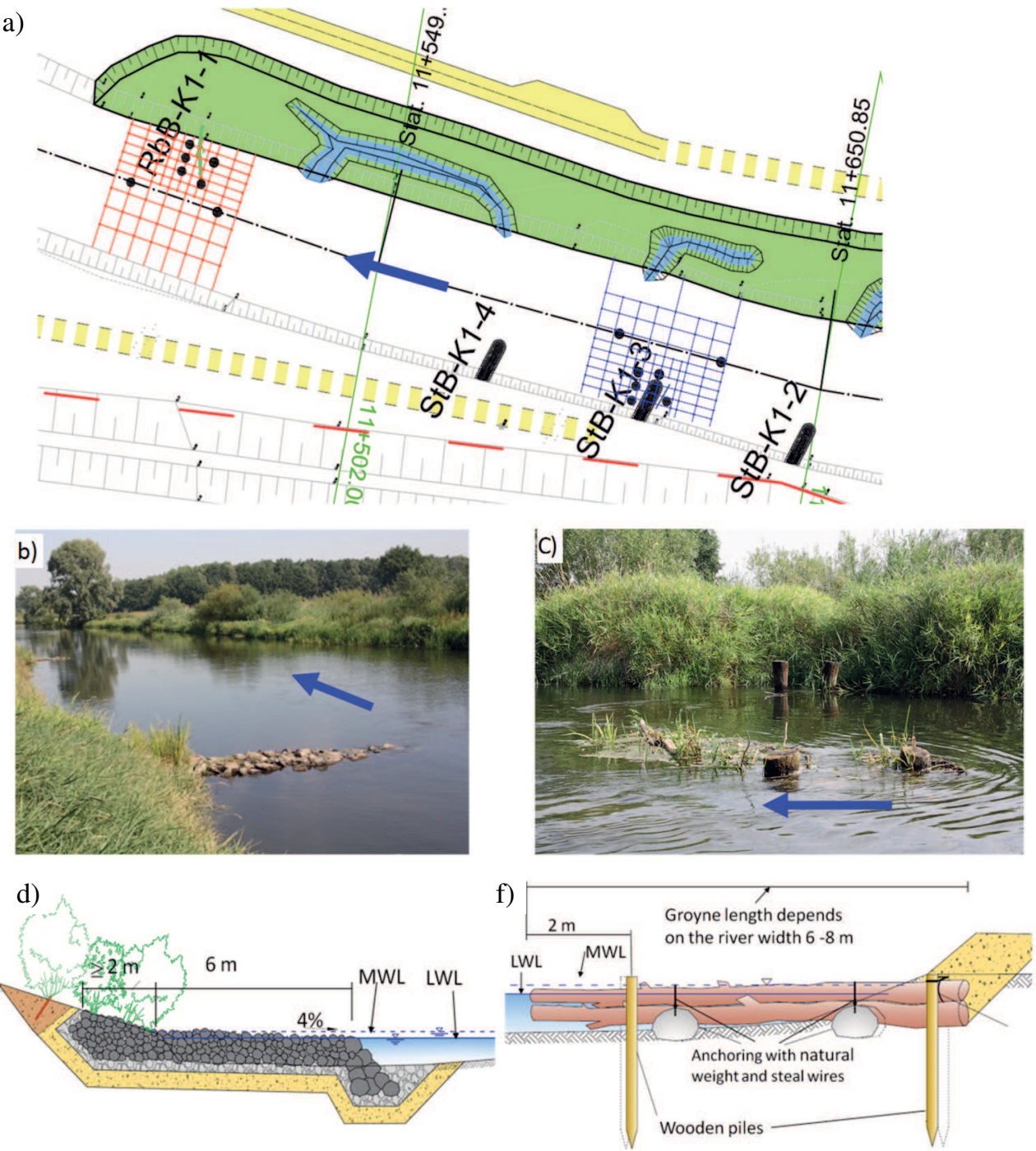

Fig. 3. (a) Layout of the measurement site (grids for velocity measurements, dots for bed material samples), (b) photo of stone groyne, (c) photo of wooden groyne, (d) and (f) cross sections of the stone and wooden groynes respectively, modified form the construction drawing by gerstgraser, Ingenieurbüro für Renaturierung.

\subsection{Measurements equipment}

The flow velocity was measured using a flow current meter from SEBA Hydrometrie $\mathrm{GmbH}$ attached to a steal rod. The steel rod has a scale, which was used to measure the water depth as well as the vertical location of the current meter above the bed. To fix the measurements cross section, two poles connected with a measuring tape were used. The bed topography was determined relative to the water level. A gauge station $500 \mathrm{~m}$ upstream of the measurements site was used to monitor the water level. It was constant during the measurements except for the first day where it was $3 \mathrm{~cm}$ higher. The difference was considered in the analysis of the bed topography. The bed material was sampled using a grape sampler and analysed at the sediment lab of the Leichtweiß-Institute. 


\section{Results and discussion}

\subsection{Flow velocity, bed topography and bed material at the stone groyne}

The velocity distribution at the stone groyne is shown in Fig. 4, for two different levels above the bottom, corresponding to 20 and $40 \%$ of the water depth. Due to the presence of the groyne, the velocities close to the left bank were significantly reduced. The maximum velocity zone was not centred but shifted slightly towards the right bank. Stagnant water zones upstream and downstream of the groyne were observed, with areas of return flow close to the groyne in the downstream direction. In the vicinity of the groyne the highest velocity was noted at the groyne tip.
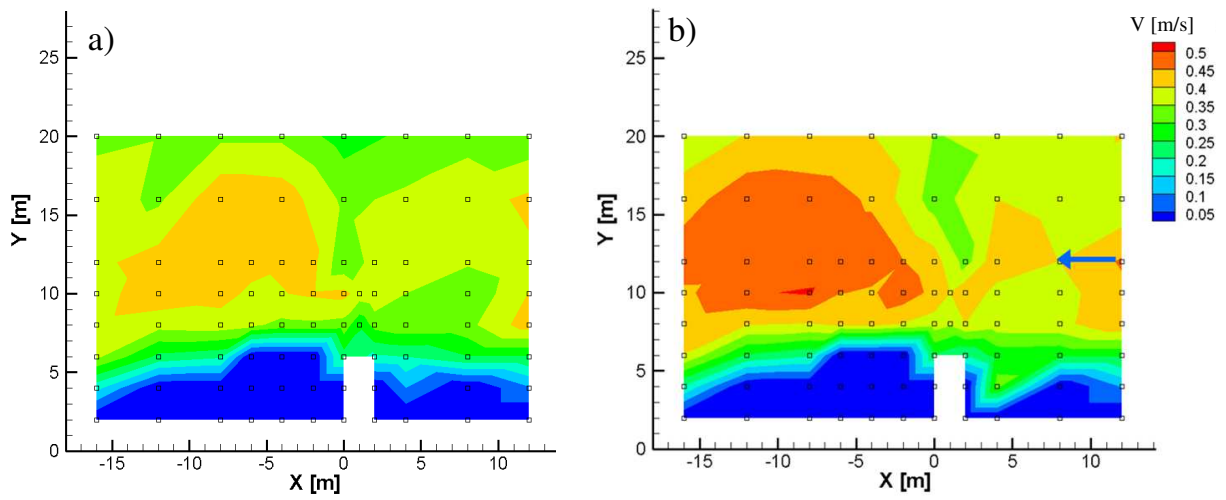

Fig. 4. Plan view of the velocity distribution at the stone groyne at different levels above the bottom, (a) $20 \%$ and (b) $40 \%$ of the water depth.

The effect of the stone groyne on the bed topography is presented in Fig. 5a. The maximum scour on the river bed was found at the groyne tip, which is typical for emerged structures (e.g. $[9,10])$ whereas the scour develops at a distinct distance downstream of the tip for fully submerged structures, e.g. shallow groynes ([11]). The scour extended in the downstream direction for about $8 \mathrm{~m}$. In addition to the scour, deposition areas were determined locally at the upstream side of the groyne, and in the lee side extending $5 \mathrm{~m}$ downstream of the groyne.

Fig. $5 \mathrm{~b}$ presents the grain size distributions of the bed material sampled at the locations given in Fig. 5a.
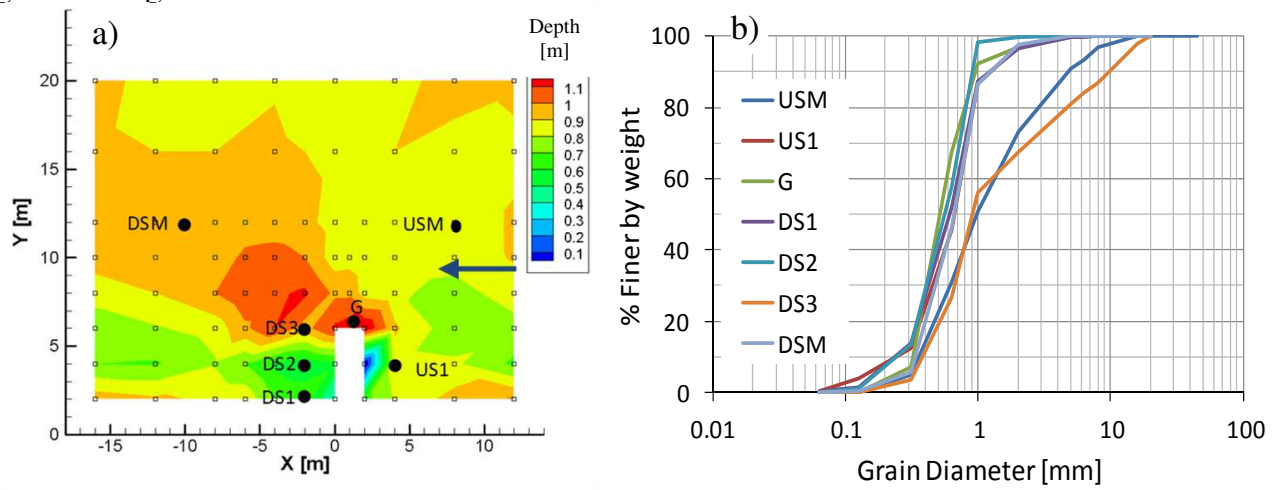

Fig. 5. (a) Bed topography with black filled circles for bed material sample locations, (b) bed material grain size distribution. 
The bed material mainly consisted of medium and coarse sand with a mean grain size of $d_{50}=0.6 \mathrm{~mm}$. Only at two locations coarser sediment was sampled. One location was in the middle of the river (USM), the other one in the scour downstream of the groyne tip (DS3).

As the second sample in the middle of the river (DSM) corresponded to the samples taken at the groyne, distinguishing between the middle of the river and the area close to the bank is not possible. Also up- and downstream of the groyne similar grain size distributions were found, and even in the scour at the groyne tip the bed material was not coarser than the average.

These inconsistencies can be explained by the fact, that small dunes consisting of medium to coarse sand were travelling over the surface made of the coarser sediment shown in Fig. $5 b$.

It was observed during the measurements that the river bed close to the left bank was completely covered by the finer material. Due to the groyne the velocities were small (see Fig. 4a) and the sand was not transported. Towards the middle of the river, further away from the groyne, the distribution of finer and coarser sediment was patchy, i.e. the coarser material was partly covered by finer material. The scour at the groyne tip can be filled with the finer sediment which may be washed out during floods. In conclusion, the diversity of the bed material was not dominated by the groyne but by the high sand load.

A high load of sand transported in dunes even during normal flow conditions is often observed in modified rivers and often related to catchment erosion, e.g. from agricultural areas. However, a study of the sediment budget of a modified heathland river ([12]) revealed that the sediment supply from external sources was much less than from bed erosion. Also in the case of the River Spree it can be assumed that the dunes result from vertical sorting of the bed material due to shear stresses which are too high for a natural river. However, this needs to be investigated in further studies.

\subsection{Flow velocity, bed topography and bed material at the wooden groyne}

The wooden groyne consisted of several trunks arranged vertically allowing the flow to pass between the trunks. The trunks were fixed to wooden piles up- and downstream of the tip. The trunks were not attached to the bank (Fig. 6) and local bank erosion was observed between the bank and the trunk, allowing water to flow between the bank and the groyne toe. The structure was slightly submerged during the measurements (less than $10 \mathrm{~cm}$ under water in the middle of the groyne).

The configuration of the wooden groyne resulted in the flow pattern shown in Fig. 7. The velocities downstream of the groyne were reduced compared to the approaching flow upstream. Although the downstream velocities were reduced, no dead water zone or recirculating areas were noted. A similar scour at the groyne toe was noted for shallow groynes [13], which was attributed to overtopping of the structure. The low velocity zone on the left bank was caused by branches of a large tree which were hanging in the water.

Fig. 8 shows the bed topography. The presence of the wooden groyne resulted in two scour areas around the groyne (Fig. 8a). One scour area was found at the groyne tip and a second larger scour zone was noted around the mid section of the groyne. The second scour started around $1 \mathrm{~m}$ upstream of the groyne and extended for about $6 \mathrm{~m}$ downstream of it. The depth of the scour at the middle of the groyne was almost the same of the one at the groyne tip. A deposition area was found $12 \mathrm{~m}$ downstream of the groyne. The large scour area at the right bank was caused by the aforementioned branches of the large tree.

The analysis of the bed material showed that upstream of the groyne at US1, and at the groyne tip, the bed consists of fine sand (Fig. 8b). The coarsest bed material was found at DS2 in the middle of the scour downstream of the groyne. The composition of the fine 
sediment and, especially, of the coarser material was very similar to the bed material found at the stone groyne.

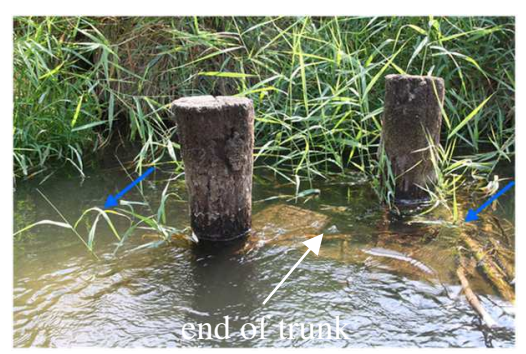

Fig. 6. Scour and flow at the wooden groyne toe.
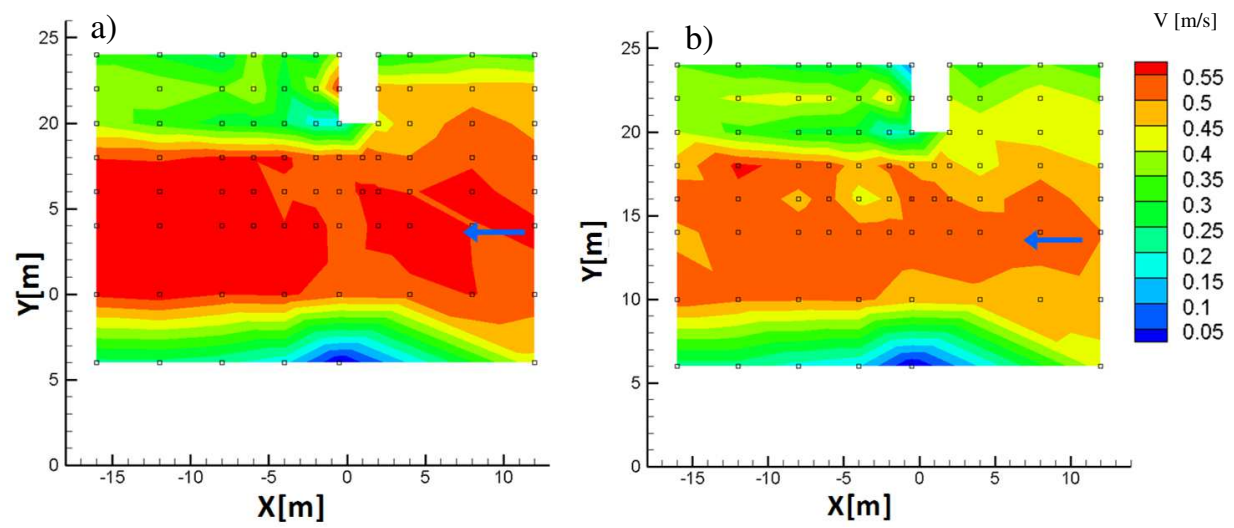

Fig. 7. Velocity distribution at the wooden groyne at different levels above the bottom (a) $80 \%$ and (b) $40 \%$ of the water depth.
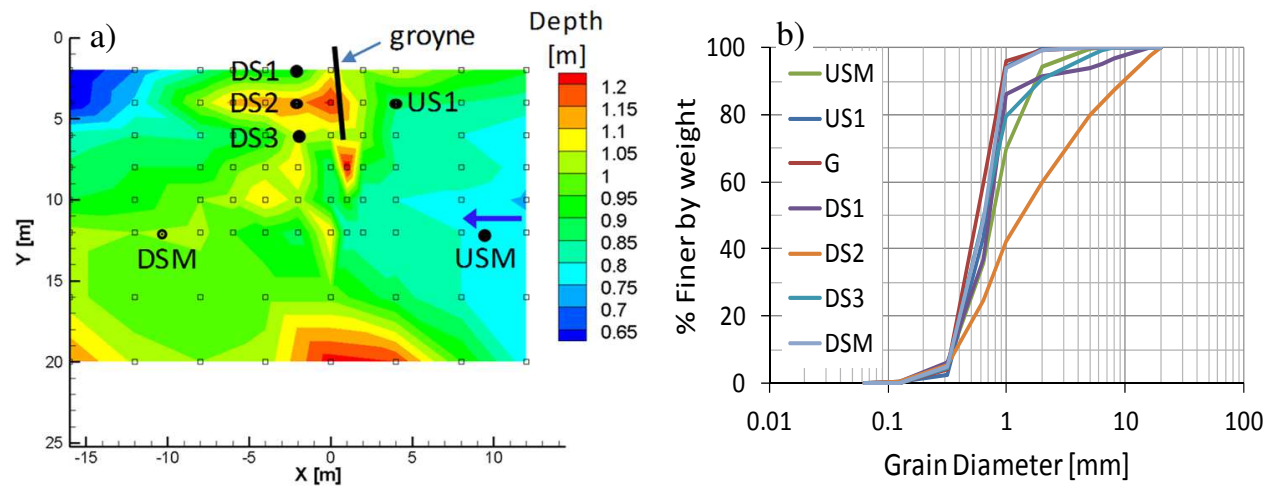

Fig. 8. (a) Bed topography with black filled circles for bed material sample location and (b) bed material grain size distribution.

\section{Conclusions}

The analysis of field measurements at the stone and the wooden groynes showed the effect of each groyne type on the flow pattern, bed topography, and bed material. The impermeable and mainly emerged stone groyne created a stagnant water zone and a return 
water zone downstream of the groyne. The wooden groyne reduced the velocity, but no stagnant water zone was noted. This can be due to the submergence of the wooden groyne and to the flow through and underneath it. The maximum bed scour was found at the groyne tip in the case of the stone groyne, with a deposition area upstream and downstream of the structure. In the case of the wooden groyne, a scour at the groyne tip also developed; however, a second scour of the same order of magnitude was found at the middle of the groyne. The scour started upstream of the groyne and extended for several meters downstream of it. The analysis of the bed material revealed that a high load of medium to coarse sand dominated the situation. Dunes were travelling over a somewhat coarser bed in the middle of the river. For both groynes the scours at the tip were filled with the finer material whereas the scours not connected to the tip consisted of the coarser sediment. The bed close to the bank up- and downstream of the stone groyne was composed mainly of sand The higher diversity of the bed topography and less deposition of fine material in case of the wooden groyne may lead to the conclusion that this way of constructing a groyne for creating habitats is better than the stone groyne, however, during the measurements many fishes were observed also in the scour downstream of the stone groyne. The analysis of the effect of groyne type on the flow field and bed morphology, such as the one presented here, can serve as basis for selecting a type of groyne, wooden or stoney, depending on the intended results in river restoration projects.

Acknowledgments: This work was supported by the 7th Framework Programme of the European Union, (Marie Curie - FP7-PEOPLE-2012-ITN), which funded the Initial Training Network (ITN) HYTECH 'Hydrodynamic Transport in Ecologically Critical Heterogeneous Interfaces', N. 316546.

\section{References}

1. M. Hentschel, B. Hentschel, Ecohydrol., 6, 598-610 (2013)

2. J.A. Gore, G.E. Petts, CRC Press (1989)

3. S.M. Scurlock, C.I Thornton, D.C. Baird, S.R. Abt, J. Hydraul. Eng., 141(2), (2015)

4. F.D. Shields Jr., C.M. Cooper, S.S. Knight, J. Hydraul. Eng., 121(6), 494-502 (1995)

5. C. Gerstgraser., H. Zank, Naturschutz und Landschaftsplanung, 44(10), 293-299 (2012)

6. M. Nones, C. Gerstgraser, Hydrodynamic and Mass Transport at Freshwater Aquatic Interfaces: 34th International School of Hydraulics. GeoPlanet: Earth and Planetary Sciences, Springer, 167-182 (2016)

7. S. Hilt, I. Schönfelder, A. Rudnicka, R. Carls, N. Nikolaevich, A. Sukhodolov, C. Engelhardt, Palaeomemanders, River Research and Applications, 24, 310-329 (2008)

8. I. Schnauder, C. Gerstgraser, M. Nones, M. Schuster, S. Giebler, 39. Dresdner Wasserbaukolloquium (2016).

9. D. Fang, J. Sui, R.W. Thring, Int. J. Sediment Res., 21 (2), 89-100 (2006).

10. R.A. Kuhnle, C.V. Alonso, J. Hydraul. Eng., 128 (12), 1087-1093 (2002).

11. R. Möws, Ka Koll, Proceedings of River Flow 2014, 1447-1454(2014).

12. A. Schulte-Rentrop, Ka. Koll, J. Aberle, A. Dittrich, Acta Geol Pol, 53(4), 553-565 (2005)

13. B. Zaid, Ka. Koll, Proceedings of River Flow 2016, 1286-1292 (2016) 